\title{
ARTIGO
}

\section{Revendo o debate quantidade-qualidade: tendências da pesquisa na Biblioteconomia e Ciência da Informação}

\section{Reviewing the quality-quantity debate: research trends in Librarianship and the Information Science}

Ely Francina Tannuri de OLIVEIRA ${ }^{1}$

R E S U M O

Este artigo apresenta algumas controvérsias sobre métodos qualitativos e quantitativos na ciência em geral e, mais especialmente, na Biblioteconomia e Ciência da Informação. Analisa a problemática dos dois métodos de modo a conhecer as bases do debate existente, e verifica quais têm sido as tendências da pesquisa na Biblioteconomia e Ciência da Informação quanto à escolha dos dois métodos.

Palavras-chave: métodos qualitativos e quantitativos, Biblioteconomia, Ciência da Informação, metodologia, pesquisa.

\section{A B S T R A C T}

This article shows some controversies over qualitative and quantitative methods in the scientific worls in general, but, more specificaly Librarianship and the Information Science.

\footnotetext{
${ }^{1}$ Doutora, Professora Assistente, Departamento de Ciência da Informação, Curso de Biblioteconomia, Faculdade de Filosofia e Ciências, Universidade Estadual Paulista, UN ESP. Av. H ygino M uzzi Filho, 737, Campus Universitário, 17525-900, Marília, SP, Brasil. E-mail: tannuri@terra.com.br Recebido para publicação em 28/5/2003 e aceito em 25/7/2003.
} 
It analyses the two methods in order to know the bases of the existing debate, and scrutinizes what have been the trends in Librarianship and the Information Science research with regard to the choice of the two methods.

Key words: qualitative and quantitative methods, Librarianship the Information Science, methodology, research.

\section{N T R O D U Ç Ã O}

As controvérsias surgidas nas últimas décadas sobre a questão da quantidade-qualidade e as polêmicas sobre metodologias quantitativas e qualitativas, no âmbito da pesquisa em geral e na pesquisa em Biblioteconomia e Ciência da Informação, trazem algumas indagações de ordem epistemológica que apontam para a ausência de uma estrutura teórica mais sistematizada na área. Nesse contexto, a pesquisa em Biblioteconomia e Ciência da Informação adquire grande importância, pois através dela se faz avançar o conhecimento. Nos diferentes campos do conhecimento, a preocupação metodológica é acompanhada de implicações tanto no âmbito do pesquisador, como do fenômeno estudado, como na natureza do campo de conhecimento onde se realiza. Este artigo aponta algumas polêmicas, vantagens e desvantagens de ambos os tipos de métodos, objetivando analisar a problemática dos métodos quantitativos e qualitativos, de modo a conhecer algumas das controvérsias existentes; e verificar quais têm sido as tendências de pesquisa na Biblioteconomia e Ciência da Informação.

\section{Diferentes Abordagens}

Norteadas por princípios positivistas, as abordagens quantitativas dominaram as pesquisas e as investigações nos diferentes campos das ciências, até a década de 70 . Novos paradigmas, partindo de outros pressupostos, passaram a contestar a pesquisa experimental e quantitativa como único padrão metodológico para construção e legitimação do conhecimento, especialmente nas áreas de ciências humanas e sociais, trazendo novos enfoques e novas abordagens.

Até então, já desde o século XVII, "os impactos promovidos pelos sucessos dos métodos das ciências físicas sobre o mundo moderno, decorrentes dos avanços científicos, influenciaram amplamente e com expressiva repercussão a condução teórica e prática das pesquisas subseqüentes" (BUFREM, 2001). O prestígio da pesquisa experimental era tal que se afirmava "que a ciência seria uma estrutura assentada sobre fatos" (BUFREM, 2001). O pensamento dominante enfatizava a importância da experimentação e da possibilidade de quantificá-la e essa trajetória do pensamento, fundamentada na experiência, passa a ser apreciada também para as ciências humanas.

Porém, surgem novas possibilidades metodológicas, cujos critérios de objetividade não seriam dependentes apenas de considerações quantitativas ou de modelos irrefutáveis: instaura-se uma polêmica sobre as possibilidades metodológicas dos modelos quantitativos e qualitativos de pesquisa, especialmente nas ciências humanas e sociais.

Para Richardson (1989), cientista social, o que difere uma abordagem da outra é o emprego da quantificação. O autor em questão afirma:

O método qualitativo difere em princípio do quantitativo à medida que não emprega um instrumental estatístico como base do processo de análise de um problema. Não pretende numerar ou medir unidades ou categorias 
homogêneas (RICHARDSON, 1989, p.38).

O autor não vê incompatibilidade entre um e outro método, considerando que um método pode servir de aporte ao outro, sendo necessário "na medida do possível integrar pontos de vista, métodos e técnicas" (RICHARDSON, 1989).

Grover \& Glazier (1985), investigadores na área da Biblioteconomia, preocupam-se com a lógica de um e outro método. Consideram que nas metodologias quantitativas a lógica de inferência está próxima da lógica matemática, enquanto que a lógica da inferência usada nas qualitativas está próxima da lógica das classes. As últimas requerem a coleta de dados, análise e postulação de uma generalização. Os métodos quantitativos usam o mesmo processo, invertendo a ordem dos elementos, isto é, uma generalização é assumida primeiramente e em seguida testada em um conjunto de dados.

Ambos os métodos, segundo esses estudiosos, compartilham de uma base comum de empirismo, e os dois métodos enfrentam problemas envolvidos na formulação dos conceitos.

Um salto (mudança) intuitivo é requerido, em qualquer caso, dos dados para a relação, quaisquer que sejam as metodologias usadas para coletar os dados (GROVER \& GRAZIER, 1985, p.253).

Os autores defendem ainda a idéia de que o melhor método é aquele que é mais apropriado à natureza do problema em estudo, não existindo, em si, um método melhor que o outro. Outros autores, no entanto, sustentam que as divergências advêm de oposições fundamentadas em concepções epistemológicas distintas e que, portanto, essas divergências não se configuram nos limites de procedimentos e técnicas, mas refletem confrontos mais radicais que remetem a posturas filosóficas e teóricas distintas.

Smith \& Heshusius (1986), pesquisadores americanos da área de educação, fazem uma revisão histórica na relação entre as duas abordagens em pesquisa, distinguindo três fases. A primeira, que durou até recentemente, foi caracterizada pela defesa das diferenças fundamentais entre as duas abordagens, diferenças relativas quanto ao pressuposto teórico e quanto ao procedimento. A abordagem interpretativa da pesquisa social ofereceu desafio direto ao positivismo, em posição de claro conflito.

Na segunda fase, de transição, decresceu a preocupação com as diferenças de paradigma, passando-se a enfatizar mais os procedimentos de pesquisa; fez-se presente a "coexistência pacífica entre os dois métodos". Na terceira fase, a atual, a preocupação com os pressupostos é mínima. As diferenças referem-se principalmente à área de procedimentos e a atitude geral é de compatibilidade e cooperação mútua.

Smith \& Heshusius (1986) consideram que as preocupações com os pressupostos filosóficos que caracterizaram inicialmente 0 debate quantitativo-qualitativo foram substituídas, com o passar do tempo, por outras que dizem respeito apenas à construção de métodos de pesquisa qualitativa, que garantam a eles a mesma objetividade da pesquisa quantitativa. Criticam a despreocupação paradigmática na prática da pesquisa, e consideram que a busca de procedimentos que garantam aos pesquisadores como fazer a pesquisa qualitativa transformaram-na em uma modalidade da quantitativa. Criticam ainda, de forma incisiva, a postura de compatibilidade e cooperação que leva ao término do debate entre as duas abordagens. Afirmam que:

(...) o principal argumento é que - apelo à compatibilidade, deixando de lado o de síntese, não pode ser mantido. Além disso este 'salto para a compatibilidade', apressado e injustificado, tem o infeliz efeito de encerrar uma importante e interessante conversa (SMITH \& HESHUSIUS, 1986, p. 4). 
Thiollent (1984) apresenta, a respeito da metodologia das ciências sociais, uma pluralidade de níveis e de abordagens que vão desde "metodologias gerais" de nível epistemológico, passam por metodologias mais especiais até "técnicas quantitativas", tais como "amostragem, inferências, correlações, análise fatorial, pacotes de computação, etc.". O autor sintetiza uma diversidade de opções relativas à temática metodológica,

(...) que não podemos resumir numa oposição qualitativo versus quantitativo... podemos distinguir uma pluralidade de enfoques que dão privilégio quer aos aspectos qualitativos, quer aos quantitativos. Do ponto de vista do ideal geral da ciência, pensamos que uma articulação dos dois tipos de aspectos é mais satisfatória. Mas, dependendo do assunto e da abrangência da observação, certas pesquisas são principalmente qualitativas ou principalmente quantitativas (THIOLLENT, 1984, p. 46).

Sem ser eclético, ele opta por enfoques que privilegiam a articulação dos aspectos qualitativos e quantitativos, dependendo da natureza do problema em estudo, ou de aspectos distintos da pesquisa, tais como macro ou micro abrangência, observação passiva ou ativa e, ao contrário de Smith \& Heshusius (1986), sem preocupação com pressupostos teóricos e filosóficos.

Thiollent (1984) afirma ainda que,

$\mathrm{Na}$ realidade, qualquer fato social ou educativo possui aspectos que podemos descrever em termos quantitativos (tamanho da população, repartição por categorias, freqüência ou intensidade dos acontecimentos observados etc.) e em termos qualitativos (significação, compreensão, 'rotulagem' etc.) (THIOLLENT, 1984, p. 46).

Outro argumento que o autor apresenta, favorável às análises quantitativas, diz respeito à concepção crítica de pesquisa social:

(...) sem dúvida é do tipo principalmente qualitativo. No entanto, se associarmos à idéia de crítica, uma função de elucidação, de denúncia ou outros tipos de contribuição ao debate político em torno dos problemas sob observação, podemos considerar que os números podem exercer uma função crítica (THIOLLENT, 1984, p. 48).

Para o autor, as quantificações, dados e mensurações fortalecem os argumentos e constituem indicadores importantes para as análises qualitativas.

Esses diferentes pontos de vista relativos às quantificações, quer o de Smith \& Heshusius (1986), que defendem a continuidade da polêmica, quer o de Grover \& Glazier (1985), que analisam a questão metodológica do ponto de vista da lógica da inferência, quer o de Richardson (1989) e Thiollent (1984), que contemplam as técnicas independentemente dos pressupostos teóricos, devem ser considerados no presente estudo por serem objetos de debate na comunidade científica.

Se na pesquisa e no seio da comunidade científica essa questão metodológica é polêmica, no ensino, aquelas disciplinas ou abordagens de pesquisa que utilizam quantificações acabaram por ter seu prestígio diminuído perdendo espaço no currículo. A quantificação, muitas vezes, é identificada com postura superada, reacionária, positivista e anti-dialética. $\mathrm{O}$ "modismo" dos números, que vigorava até os anos setenta, foi dando lugar à hegemonia fenomenológica e interpretativa. O que são as quan- 
tidades, senão indicadores que nos levam a analisar as qualidades do objeto de estudo?

A concepção dialética da história considera que os aspectos quantitativos e qualitativos devem ser rigorosamente levados em conta na planificação de qualquer trabalho. No pensamento gramsciniano, quantidade e qualidade são dois aspectos do mesmo problema, apenas que o quantitativo é mais controlável por ser mais facilmente mensurável, não existindo dicotomia entre eles.

Afirmar, portanto, que se quer trabalhar sobre a quantidade, que se quer desenvolver o aspecto corpóreo do real, não significa que se pretenda esquecer a 'qualidade', mas, ao contrário, que se deseja colocar o problema qualitativo de maneira mais concreta e realista, isto é, desejase desenvolver a qualidade pelo único modo no qual tal desenvolvimento é controlável e mensurável (GRAMSCI, 1966, p. 50).

Ainda no entender de Gramsci (1966), não existem ciências por excelência e não existe um método por excelência, 'um método em si'. Toda pesquisa científica cria para si própria um método adequado, uma lógica própria, cuja generalidade e universalidade consiste somente em ser 'coerente com o objetivo' (MANACORDA, 1990, p.196).

Além dos argumentos utilizados pelos investigadores ligados diretamente à área da metodologia científica, o pensamento de Gramsci contextualiza a relação quantidade-qualidade de forma mais ampla. Considera quantidade como indicador da qualidade, isto é, a quantidade como forma de materialização da qualidade.

$\mathrm{Na}$ verdade, a unidade entre as abordagens quantitativa e qualitativa da pesquisa vem sendo defendida pelos pós-positivistas, pelos materialistas dialéticos e pelos integrantes da Escola de Frankfurt, os quais rejeitam o dogma da distinção entre quantidade e qualidade.

Em suma, no contexto do presente estudo, trata-se a questão de análises quantitativas independentemente da fundamentação epistemológica da pesquisa, em articulação com as análises qualitativas desses dados. Isso não implica que as técnicas de pesquisa possam ser usadas como instrumentos neutros; elas são meios de obtenção da informação, cujas qualidades, limitações e distorções devem ser analisadas no contexto das metodologias utilizadas. Assim, a pesquisa quantitativa não se coloca em oposição à qualitativa.Toma-se como pressuposto que as duas convergem para a complementaridade mútua, sem vincular os procedimentos e técnicas a questões metodológicas e paradigmáticas, ou seja: o tratamento quantitativo não se vincula exclusivamente ao positivismo, nem as abordagens qualitativas, ao pensamento interpretativo (fenomenologia, dialética, hermenêutica, entre outras).

\section{Tendências da pesquisa em Biblioteconomia e Ciência da Informação}

Embora nos limites desse estudo não tenha sido possível fazer um levantamento exaustivo das tendências da pesquisa em Biblioteconomia e Ciência da Informação, é importante contemplar o assunto e focalizar, mais especificamente, a questão dos tratamentos quantitativos e qualitativos na pesquisa.

Investigando a literatura recente relativa à pesquisa na área, registrou-se grande preocupação com problemas relativos à metodologia, produção do conhecimento na área e paradigmas teóricos. Essa preocupação tem levado os estudiosos da área, principalmente nos últimos dez anos, a refletir e retomar algumas questões 
metodológicas que, até então, tinham sido aceitas de forma tácita e consensual. Problemas relativos a pressupostos teóricos, construção do objeto de conhecimento, que até o início da década de 80 não constituíam preocupação para os estudiosos e pesquisadores brasileiros da área, passam a ser temática freqüente nos trabalhos.

Na esfera internacional, pode-se considerar que a pesquisa em Biblioteconomia inicia-se em 1928 na Graduate School, na Universidade de Chicago, EUA, com realização de extensos surveys sobre os mais diversos problemas, tais como, padrões e hábitos de leitura, bibliotecas públicas e, mais tarde, bibliotecas universitárias. Outro país que se destacou na pesquisa foi a Inglaterra, onde, já na década de 50 , as associações profissionais cuidaram de incrementar as pesquisas na área.

É importante assinalar que, até os anos setenta, a pesquisa em Biblioteconomia buscou apoio no paradigma teórico dominante na análise sociológica, ou seja, estrutural-funcionalismo e no paradigma vigente nas análises psicológicas, o que deu lugar à larga utilização de técnicas empíricas e quantitativas (MOSTAFA et al., 1992)

No Brasil, até 1972, segundo Garcia (1972, p. 8):

desconhece-se qualquer iniciativa significativa no campo de pesquisa em Biblioteconomia. Entre os bibliotecários, especialmente aqueles mais bem informados destes avanços no plano internacional, tem havido grande preocupação com o assunto, e recomendações têm sido feitas no sentido de que as escolas de Biblioteconomia assumam, através de cursos e programas de pesquisa, a responsabilidade de iniciar esta atividade no Brasil (o que exigiria como condição prévia a instalação de cursos de Pós-
-Graduação, além de outras providências).

Naquela época, problemas relativos à epistemologia e construção do conhecimento biblioteconômico passaram a ser questões para os estudiosos. Tais questões ultrapassavam as limitações determinísticas da ótica positivista que imperava nas investigações da área, até então. Entre as pesquisas, em geral de abordagens descritivas e funcionalistas, começaram a aparecer aquelas que utilizam abordagens dialéticas, onde a biblioteca e as questões da informação são vistas em função de seus determinantes histórico-sociais, tal como se deu na ciência em geral.

Assim, as investigações evoluem de um enfoque reducionista, em que a problemática biblioteconômica é encarada de forma isolada e desvinculada de sua relação com a sociedade, para um abordagem mais totalizante, assentada nas questões de fundo da relação bibliote$\mathrm{ca} /$ sociedade, tais como: função social da biblioteca, instâncias políticas e culturais da biblioteca, o bibliotecário como agente de informação e transformação, e outras.

Dentro da abordagem histórica e dialética, Mostafa (1981, p.48) registra:

\begin{abstract}
a biblioteca e/ou os seus agentes não existem soltos na sociedade mas estruturados e com ela constituindo a estrutura social; nessa constituição a biblioteca troca relações com outras instituições extrínsecas a si mesma e os agentes do trabalho bibliotecário com outros agentes do trabalho social. Nesse sentido, a biblioteca é sujeito e objeto da sociedade e por isso mesmo não pode ser analisada em apenas um de seus papéis.
\end{abstract}

Optando pela dialética materialista, vislumbra novas formas de captar a essência das 
práticas biblioteconômicas, pois, nessa ótica, os fenômenos apresentam-se de forma que não revelam seu conteúdo verdadeiro. O papel da investigação científica é buscá-lo, indo além da descrição, relação e determinação de leis. Mostafa (1981, p. 49) afirma ainda:

utilizar o materialismo histórico não significa prescindir dos dados empíricos ou da observação, mas esses dados, são, a um só tempo, partida e chegada da análise. Eles exprimem alguma coisa que não está à vista. Desde que o objeto de estudo não seja teórico, a empiria e a observação é necessária, mas nunca suficiente. O fato empírico é uma forma particular da realidade, início abstrato e relativo.

Para a estudiosa, o enfoque descritivo e empirista é necessário, mas insuficiente para explicar os fenômenos e problemas da área, quando restritos aos limites da pura narração. A autora sugere, em outro trabalho, aos estudiosos da metodologia da pesquisa: "Temos que mediar a quantidade com a qualidade" (MOSTAFA, 1983, p.228).

Segundo Souza (1986, p.192), outro estudioso do assunto, a Biblioteconomia não possui até hoje um corpo definido de teorias e leis, como outras ciências sociais ou exatas. Apóia-se, no entanto, em alguns princípios e teorias que fazem dela "quase uma ciência", como por exemplo, os "princípios de Ranganathan", que hoje estão sendo retomados por vários autores da literatura internacional para estudo, com vistas à constituição de um referencial teórico para a área. Lancaster considera que esses princípios são relevantes hoje como foram há 60 anos; ao interpretar o primeiro princípio de Ranganathan - qual seja, "livros são para o uso" - sugere que a investigação objetiva, empírica, deve substituir abordagens subjetivas ou puramente impres- sionistas. A propósito, afirma Figueiredo (1992, p.187):

\begin{abstract}
Conhecendo-se a obra de Lancaster, sabe-se que ele está se referindo a métodos, como consulta a fontes de coleções bibliográficas e a especialistas quando se refere à avaliação de coleções com abordagens impressionistas; estes métodos devem ser utilizados juntamente com os quantitativos.
\end{abstract}

Outros estudiosos estão investigando e procurando alternativas metodológicas com preocupação de contextualização filosófica, sem contudo chegarem a propor um procedimento ou abordagem única de pesquisa na área, mas buscando aquelas que melhor possam captar o fenômeno em estudo.

No momento atual, no Brasil, "a pesquisa em Ciência da Informação, tal como pôde ser analisada a partir dos relatórios Capes referentes aos anos de 1998, 1999 e 2000, aponta claramente para um processo de constituição histórica da área" (SMIT, 2002, p.25). Essa observação confirma-se especialmente pelos programas de pósgraduação que, de origem, nasceram de uma graduação em Biblioteconomia e são responsáveis hoje pela maior parte da pesquisa desenvolvida, no Brasil, na área. Observa-se ainda que o tema "pesquisa" tem sido objeto de estudo de encontros de profissionais e investigadores da área. Cita-se, por exemplo, o VI Encontro Nacional de Ensino de Biblioteconomia e Ciência da Informação (ENEBCI), promovido pela Associação Brasileira de Ensino de Ciência da Informação (ABECIN), realizado em Campinas entre 30 de maio e 2 de junho, que teve como tema "A pesquisa nos cursos brasileiros de Ciência da Informação". Nele se discutiu o objeto de estudo da Ciência da Informação, a produção científica na área tanto relativa aos pesquisadores quanto aos discentes e a articulação entre ensino e pesquisa. Destaca-se, nesse encontro, a abordagem histórica de 
Ciência da Informação, feita pelo Professor Aldo Barreto, pesquisador do Instituto Brasileiro de Informação em Ciência e Tecnologia (IBICT) e docente de Pós-Graduação em Ciência da Informação da Universidade Federal do Rio de Janeiro (UFRJ), identificando três momentos, os quais denominou de "Tempos da Ciência da Informação". São eles: $1^{\circ}$ ) o tempo de Gerência de Informação (1948-1980); 2º) o tempo da relação entre informação e conhecimento (1980-1995); 3o) o tempo da Sociedade da Informação (1995 - até os dias de hoje) (KOBASHI, 2002, p.12).

Observe-se que a cada uma dessas fases, encontram-se vinculadas questões específicas de pesquisa. Segundo o autor em questão, "a primeira fase caracteriza-se pela pesquisa voltada à organização e exploração de estoques; a segunda, corresponde às pesquisas sobre cognição e recepção da informação e a terceira, às investigações sobre fluxos" (KOBASHI, 2002, p.12).

A principal linha de pensamento que se manteve através da literatura referente à metodologia da pesquisa em Biblioteconomia contempla o argumento de que esta tem os mesmos fundamentos das ciências sociais e humanas, quando seu objeto de estudo é a biblioteca, como instrumento de ação cultural que veicula informações adequadas e suficientes para o homem, situado em um momento histórico, político, social e econômico.

Assim, as investigações na área não podem prescindir, portanto, do quesito da historicidade e de abordagens metodológicas que consideram o contexto e a relação dialética entre homem e sociedade, como também do ambiente natural da Biblioteca como fonte imediata dos dados, onde o pesquisador tem contato direto com o ambiente e a situação investigada. A propósito desse ambiente natural da Biblioteca, é importante destacar que o mundo biblioteconômico é real e objetivo. Existe um "mundo" enumerável e mensurável dentro da Biblioteca, com seus livros, periódicos, fluxo de informação, que deve ser avaliado quantitativamente.

Questões surgem naturalmente quando em contato com esse espaço. Qual o tamanho do acervo? Ele atende ao número de usuários? Quais os periódicos mais produtivos dentro de determinada área? Qual fração da coleção atende a maior parte da demanda? Sob quais indicadores decide-se um sistema de compra? Em qual área do conhecimento o fluxo de informações é mais intenso? O significado numérico do fluxo de documentos faculta inferências sobre a importância da informação veiculada? A mensuração da demanda da informação articula-se com o processo de planejamento e avaliação de sistemas de informação? Quais os custos em serviços informacionais? Para descarte de material utilizam-se somente critérios qualitativos, ou os quantitativos constituem indicadores importantes? Para avaliar coleções necessitase também de quantificações? Como determinar os periódicos prioritários, cuja assinatura interessa manter em um momento de corte orçamentário? De que forma se conhecem os autores mais produtivos em suas respectivas áreas? Como reverter situações ou justificar aumento de solicitação de recursos financeiros sem quantificar: somente a partir de considerações qualitativas sobre o contexto?

Com quais parâmetros responde-se a essas questões? Provenientes da intuição? Do bom senso? Da observação? Do mero "discurso opinatório"? Ou através de indicadores numéricos que possam responder às questões com certa margem de confiança?

Saber eleger instrumentos apropriados no trato dos problemas biblioteconômicos é estar capacitado para fazer a leitura do cotidiano profissional, através também da "matematização" e problematização dessa realidade, construindo novos padrões de conhecimento na área, dentro do contexto brasileiro, e não somente aplicando padrões e fórmulas prontas, já existentes, advindas de outras realidades. 
O bibliotecário lida com grande volume de dados, tanto de entrada como de saída, que necessitam ser processados, quantificados, comparados e analisados. No entanto,

os bibliotecários têm sido relutantes em submeter os dados do cotidiano profissional à análise quantitativa rigorosa e utilizar metodologias estatísticas como um dos aspectos do método científico (BUSHA \& HARTER, 1980, p.192).

O conhecimento das técnicas de análises quantitativas, segundo esses autores, pode ajudar os bibliotecários nas interpretações corretas tanto dos dados relativos às observações registradas diariamente como de outros dados advindos dos questionários, testes, surveys e outros instrumentos utilizados para se obter informações concernentes aos fenômenos biblioteconômicos. Apesar das críticas aos modelos quantitativistas e às observações estatísticas, não se pode deixar de encontrar neles indicadores e imagens de sínteses, "que representam não as situações individuais, mas a média dessas situações" (BESSON, 1995, p.32). Na verdade, as críticas ao modelo positivista de ciência e às teorias que esse modelo abriga estenderam-se aos procedimentos e técnicas empíricas e quantitativas, utilizadas em larga escala. Em tais circunstâncias, passou-se, com freqüência, à rejeição das técnicas quantitativas, quando o desejável seria utilizá-las de conformidade com suas possibilidades e limitações. Um dos desvios de compreensão é acreditar que "os estatísticos podem fazer com que os números digam o que quiser" (BESSON, 1995, p.37), observação falaciosa e que deturpa a realidade. As questões, antes arroladas, dizem respeito diretamente à formação profissional. 0 profissional munido do instrumental adequado certamente chega com mais presteza ao equacionamento e solução das referidas questões.

No campo de Biblioteconomia existem então, de um lado, objetos inanimados, externos e cognoscíveis pertencentes à realidade e, ao mesmo tempo, um mundo passível de interpretação onde a relação objeto pesquisado e investigador é inseparável. Assim, a proposta do presente artigo aponta no sentido de descartar a dicotomia entre os tratamentos quantitativos e qualitativos, nas pesquisas em Biblioteconomia e Ciência da Informação, dada a existência da associação entre objetividade e subjetividade, portanto, entre procedimentos quantitativos e qualitativos. As quantidades veiculadas pelos fenômenos em estudo devem ser interpretadas e contextualizadas dentro de uma dinâmica social ampla, de forma que as articulações entre as dimensões qualitativas e quantitativas de um mesmo fenômeno sejam exploradas para melhor compreensão do objeto de conhecimento.

Nesse sentido, é acertada a posição de Bufrem (2001, p.54), quando em publicação recente afirma que, a insistência em se contrapor, de modo dicotômico, os modelos quantitativos e qualitativos nas ciências sociais e humanas deve ser superada, especialmente nas ciências da informação, cujo caráter interdisciplinar permite uma postura mais inclinada à diversificação de diferentes enfoques na pesquisa científica.

\section{CONSIDERA ÇÕ ES FINA IS}

Nesse início de século, as grandes mudanças tecnológicas e a globalização, têm impactado a Ciência da Informação, levando a uma redefinição contínua de seu conteúdo e à revisão de seus objetivos. Assim, despontam novas possibilidades de pesquisa, com novos enfoques. As bibliotecas virtuais, os periódicos científicos online e os correios eletrônicos avizinham um novo mundo de informação. Entretanto, o panorama epistemológico traçado nesse artigo, passa a fazer parte da história da pesquisa em Biblioteconomia, contribuindo para construir o sistema lógico da mesma. 


\section{RE FER Ê N CIAS}

BESSON, J.L. A ilusão das estatísticas. São Paulo: Editora da Universidade Estadual Paulista, 1995.

BUFREM, L.S. Complementariedade qualitativoquantitativa na pesquisa em informação. Transinformação, Campinas, v.13, n.1, p.49-55, 2001.

BUSHA C.H.; HARTER, S.P. Research methods in librarianship. New York: Academic Press, 1980. p.192.

FIGUEIREDO, N.M. A modernidade das cinco leis de Ranganathan. Ciência da Informação, Brasília, v.21, n.3, p.186-191, 1992.

GARCIA, M.L.A. A pesquisa em Biblioteconomia. Revista da Escola de Biblioteconomia da UFMG, Belo Horizonte, v.1, n.1, p.7-11, 1972.

GRAMSCI, A. Concepção dialética da História. Rio de Janeiro: Civilização Brasileira, 1966.

GROVER, R.; GLAZIER, J. Implications for application of qualitative methods to library and information science research. Library and Information Science Research, Norwood NJ, v.7, n.3, p.247-60, 1985.

KOBASHI, N.Y. O ensino e pesquisa em foco: O VI ENEBCI (Encontro Nacional de Ensino de Biblioteconomia e Ciência da Informação). Transinformação, Campinas, v.14, n.1, p.11-15, 2002.

MANACORDA, M.A. O princípio educativo em Gramsci. Porto Alegre: Artes Médicas, 1990. p.196.
MOSTAFA, S.P. Biblioteconomia e história: uma abordagem dialética. Revista Brasileira de Biblioteconomia e Documentação, São Paulo, v.14, n.1/2, p.47-51, 1981.

MOSTAFA, S.P. A produção dos conhecimentos em biblioteconomia. Revista de Biblioteconomia de Brasília, Brasília, v.11, n.2, p.221-229, 1983.

MOSTAFA, S.P.; LIMA, A.B.A.; MARANON, E.I.M. Paradigmas teóricos da Biblioteconomia e Ciência da Informação. Ciência da Informação, Brasília, v.21, n.3, p.216-222, 1992.

RICHARDSON, R.J.; PERES, J.A.S.; CORREIA, L.M. Pesquisa Social: métodos e técnicas. São Paulo: Atlas, 1989. p.38-49.

SMIT, J.W. A pesquisa na área de Ciência da Informação. Transinformação, Campinas, v.14, n.1, p.25-28, 2002.

SMITH, J.K.; HESHUSIUS, L. Closing down the conversation: the end of the quantitative-qualitative debate among educacional inquierers. Educacional Researcher, Washington D.C., v.15, n.1, p.4-32, 1986.

SOUZA, S. Fundamentos filosóficos da biblioteconomia. Revista de Biblioteconomia de Brasília, Brasília, v.14, n.2, p.189-196, 1986.

THIOLLENT, M.J.M. Aspectos qualitativos da metodologia da pesquisa com objetivos de descrição, avaliação e reconstrução. Cadernos de Pesquisa, São Paulo, n.49, p.45-50, 1984. 